\title{
Pengembangan Sistem Informasi Rehabilitasi Korban Penyalahgunaan Napza Pada Kantor BRSKPN SATRIA
}

\section{Development of an Information System for the Rehabilitation of Drug Abuse Victims at the SATRIA BRSKPN Office}

\author{
Okta Verina Tri Utami*1, Citra Wiguna ${ }^{2}$, Dwi Mustika Kusumawardani ${ }^{3}$ \\ ${ }^{1,3}$ Institut Teknologi Telkom Purwokerto \\ ${ }^{2}$ Institut Teknologi Telkom Purwokerto
}

e-mail: 17103016@ittelkom-pwt.ac.id, citra@ittelkom-pwt.ac.id²,dwimustika@ittelkom-pwt.ac.id ${ }^{3}$

\begin{abstract}
Abstrak
Kantor Balai Rehabilitasi Sosial Korban Penyalahgunaan NAPZA Satria (BRSKPN) merupakan sebuah Unit Pelaksana Teknis Kementrian Sosial Republik Indonesia, yang mempunyai tugas untuk melaksanakan rehabilitasi sosial kepada korban penyalahgunaan NAPZA, dan berfokus membantu meningkatan peran dan fungsi sosial, serta pemulihan korban dari penyalahgunaan NAPZA. Proses bisnis yang dijalankan oleh pihak manajemen Kantor BRSKPN Satria terdiri dari melihat, mengedit, mencetak data pelayanan, data administrasi, data asesmen, data WHOQOL dan lain-lain. Terdapat permasalahan yang terjadi dalam proses rehabilitasi pada Kantor BRSKPN Satria antara lain penggunaan form manual pada lembaran kertas untuk proses pengelolaan dan pendokumentasian data rehabilitasi. Dalam hal ini diperlukan sebuah sistem informasi rehabilitasi untuk meningkatkan layanan rehabilitasi. Tujuan penelitian ini yaitu menghasilkan sistem informasi rehabilitasi korban penyalahgunaan NAPZA. Sistem informasi tersebut dirancang menggunakan metode waterfall. Metode waterfall mempunyai tahapan requirements definition, system and software design, implementation and unit testing, integration and system testing, dan operation and maintenance. Hasil penelitian menunjukkan sistem informasi rehabilitasi dapat diterapkan di Kantor BRSKPN Satria dengan metode waterfall yang telah diuji melalui tahap operation and maintenance. Sistem informasi rehabilitasi mampu meningkatkan pengelolaan dan pendistribusian informasi guna mempermudah proses pengambilan keputusan pada layanan rehabilitasi Kantor BRSKPN Satria.
\end{abstract}

Kata Kunci: Rehabilitasi, Sistem Informasi, Waterfall, Website

\section{Abstract}

The Satria Agency for Social Rehabilitation of Drug Abuse Victims (BRSKPN) is a Technical Implementation Unit of the Ministry of Social Affairs of the Republic of Indonesia, which has the task of carrying out social rehabilitation for victims of drug abuse, and focuses on helping improve social roles and functions, as well as recovery of victims of drug abuse. The business processes carried out by the management of the Satria BRSKPN Office consist of viewing, editing, printing service data, administrative data, assessment data, WHOQOL data and others. There were problems that occurred in the rehabilitation process at the Satria BRSKPN Office, including the use of manual forms on paper sheets for the process of managing and documenting rehabilitation data. In this case, a rehabilitation information system is needed to improve rehabilitation services. The purpose of this research is to produce an information system for the rehabilitation of drug abuse victims. The information system is designed using the waterfall method. The waterfall method has the requirements definition stages, system and software design, implementation and unit testing, integration and system testing, and operation and maintenance. The results showed that the rehabilitation information system could be implemented in the BRSKPN Satria Office with the waterfall method that had been tested through the operation and maintenance stages. The rehabilitation information system was able to improve the management and distribution of information in order to facilitate the decision-making process at the Satria BRSKPN Office rehabilitation services.

Keywords: Rehabilitation, Information Systems, Waterfall, Website 


\section{Pendahuluan}

Kantor BRSKPN Satria merupakan Unit Pelaksana Teknis (UPT) Kementrian Sosial Republik Indonesia, mempunyai tugas untuk melaksanakan rehabilitasi sosial kepada korban penyalahgunaan NAPZA, dan berfokus untuk meningkatkan peran dan fungsi sosial pemulihan korban dari penyalahgunaan NAPZA. Layanan yang diberikan oleh Kantor BRSKPN Satria yaitu rehabilitasi untuk korban penyalahgunaan NAPZA. Pembinaan dan penanganan masalah pembinaan terhadap korban penyalahgunaan narkotika merupakan salah satu kewajiban pemerintah. Permasalahan penyalahgunaan NAPZA merupakan sebuah permasalahan yang membutuhkan upaya penanggulangan dengan melibatkan kerja sama multidisipliner, multiselector, dan peran dari masyarakat yang dilaksanakan secara konsekuen, konsisten, dan berkesinambungan[1]. Data pasien narkoba di Pulau Jawa yang membutuhkan layanan rehabilitasi berjumlah 7,911 pasien[2]. Pada Kantor BRSKPN Satria terdapat 99 pasien yang direhabilitasi. Saat ini Kantor BRSKPN Satria memiliki empat pegawai utama, yaitu pegawai asesmen, perawat, psikolog, dan pekerja sosial untuk melakukan pelayanan rehabilitasi. Melihat kondisi tersebut pihak manajemen berinisiatif untuk meningkatkan pelayanan dari segi teknologi. Proses bisnis rehabilitasi yang berjalan dimulai dari proses intake yaitu korban mendatangi Kantor BRSKPN Satria. Proses selanjutnya yaitu asesmen yang dilakukan untuk memeriksa kandungan zat narkoba pada tubuh pasien, dan tahap ke tiga yaitu proses rehabilitasi. Terdapat empat golongan pemakai narkoba yang terdiri dari rekreasional, situasional, intensif, dan komplusif. Rehabilitasi diberikan kepada korban selama empat bulan. Proses bisnis pelayanan rehabilitasi tahun 2019/2020 ditunjukkan pada Gambar 1.

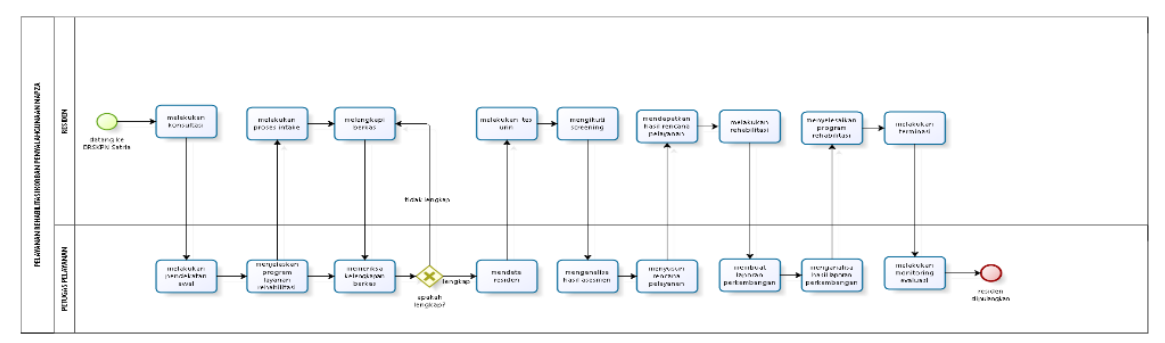

Gambar 1. Proses Bisnis Pelayanan Rehabilitasi

Berdasarkan wawancara dengan Kepala Kantor BRSKPN Satria, terdapat permasalahan yang terjadi dalam proses rehabilitasi, yaitu dokumentasi rehabilitasi masih dicatat pada form yang tertuang pada lembaran kertas, kemudian diolah dengan menggunakan Microsoft Office. Setiap perhitungan indikator keberhasilan rehabilitasi dilakukan dengan cara menuliskan hasil perhitungan oleh pegawai. Proses perhitungan, pencatatan, dan pendokumentasian dengan cara tersebut tentunya memperlembat proses pendataan dan menghasilkan data yang tidak akurat dalam pelaporan informasi korban penyalahgunaan NAPZA. Data-data rehabilitasi korban penyalahgunaan NAPZA tentunya harus dikelola dengan baik untuk proses rehabilitasi hingga pemantauan perkembangan korban. Pegawai bagian rehabilitasi juga sering mengalami human error berupa ketidaktelitian perhitungan.

Dari permasalahan yang dikemukakan, penelitian ini menerapkan teknologi informasi dalam proses pelayanan rehabilitasi dengan metode waterfall untuk peracangan sistem informasi rehabilitasi berbasis website. Dipilih berbasis website karena website merupakan lokasi yang akan dipakai untuk mengumpulkan berbagai file halaman web yang terdiri dari CSS, gambar, audio, dan lain-lain[3].

Penggunaan metode waterfall telah berhasil diterapkan pada perancangan sistem informasi monitoring dan evaluasi pembangunan pedesaan, yang terdiri dari analisa dan definisi kebutuhan sistem, perancangan sistem dan perangkat lunak, implementasi dan pengujian unit, integrase dan pengujian sistem, serta operasi dan pemelihaan sistem[4]. Penerapan metode waterfall juga telah berhasil untuk merancang sistem informasi pengolahan data persediaan barang, dan menghasilkan sistem yang terkomputerisasi. Metode waterfall cukup efektif digunakan sebagai model pengembangan sistem karena langkahlangkahnya mudah untuk diterapkan[5].

Perancangan sistem informasi rehabilitasi pernah dilakukan oleh BNNK Pematangsiantar, dan berhasil diterapkan untuk melakukan pengecekan data maupun input data mengenai rehabilitasi[6]. Pada BNN Kota Binjai juga telah berhasil menerapkan sistem informasi yang berfungsi untuk memberikan laporan-laporan mengenai penyalahgunaan narkoba pada setiap periode[7]. Badan Narkotika Nasional Sumatera Utara telah berhasil menerapkan sistem informasi pengolahan data residen menggunakan basis data terdiristribusi untuk meningkatkan efisiensi kerja[8]. Sistem informasi rehabilitasi tidak hanya

JINITA Vol. 3, No. 1, June 2021 
diterapkan pada BNN, namun dapat diterapkan pada rumah sakit untuk menangani pasien dengan sakit lutut[9].

Penerapan metode waterfall juga telah berhasil untuk merancang sistem informasi pengolahan data persediaan barang, dan menghasilkan sistem yang terkomputerisasi. Metode waterfall cukup efektif digunakan sebagai model pengembangan sistem karena langkah-langkahnya mudah untuk diterapkan[10]. Salah satu sistem informasi penjualan batik atau dapat disebut e-commerce telah berhasil dirancang menggunakan metode waterfall, sehingga memudahkan pemilik toko untuk memberikan pelayanan kepada konsumen secara lebih maksimal[11]. Penerapan metode waterfall juga telah berhasil digunakan untuk membuat sistem informasi pelayanan jasa home service berbasis web[12].

Berdasarkan literatur tersebut maka penelitian ini menerapkan metode waterfall dalam perancangan sistem informasi rehabilitasi korban penyalahgunaan NAPZA yang mampu meningkatkan proses bisnis pelayanan pada Kantor BRSKPN Satria.

\section{Metode Penelitian}

Penelitian ini menerapkan metode waterfall dalam perancangan sistem informasi rehabilitasi korban penyalahgunaan napza. Pada penelitian ini terdapat lima tahapan, yaitu requirements definition, system and software design, implementation and unit testing, integration and system testing, operation and maintenance. Tahap pengembangan sistem menggunakan metode waterfall ditunjukkan pada Gambar 2.

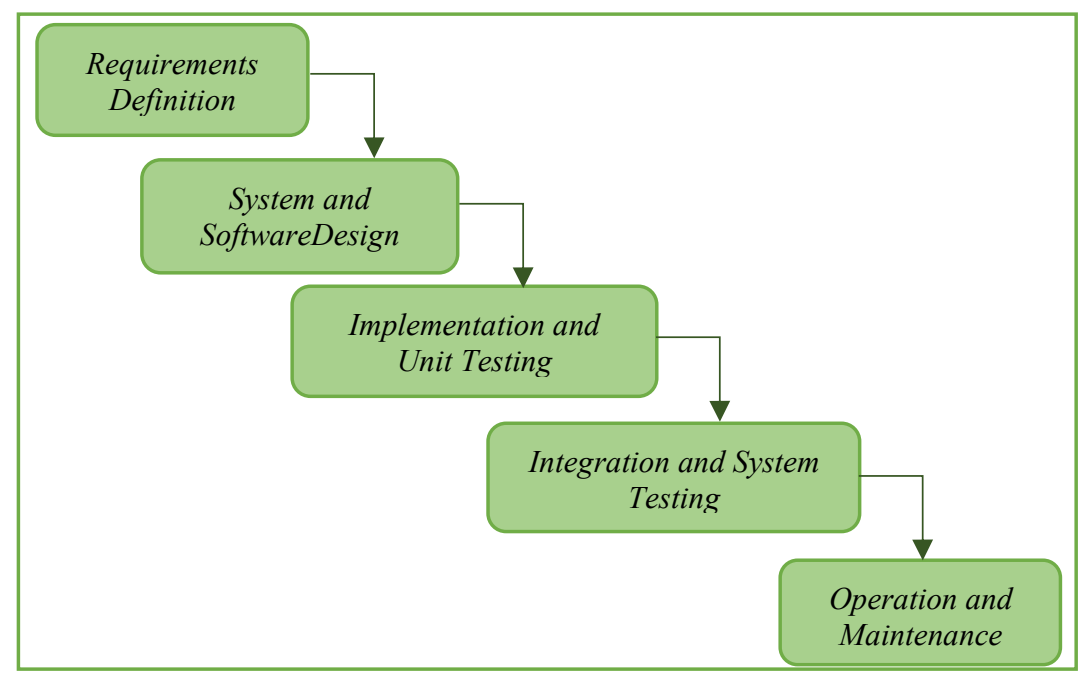

Gambar 2. Metode penelitian

1. Requirements Definition

Pada tahap pertama dilakukan untuk mengetahui proses bisnis layanan rehabilitasi Kantor BRSKPN Satria. Terdapat empat proses bisnis utama yang dijalankan oleh pegawai asesmen, perawat, pekerja sosial, dan psikolog.

2. System and Software Design

Pada tahap kedua dilakukan penyusunan kebutuhan untuk merancang sistem informasi rehabilitasi korban penyalahgunaan NAPZA. Terdiri dari use case dan class diagram. Use case diagram admin dapat dilihat pada Gambar 2. 


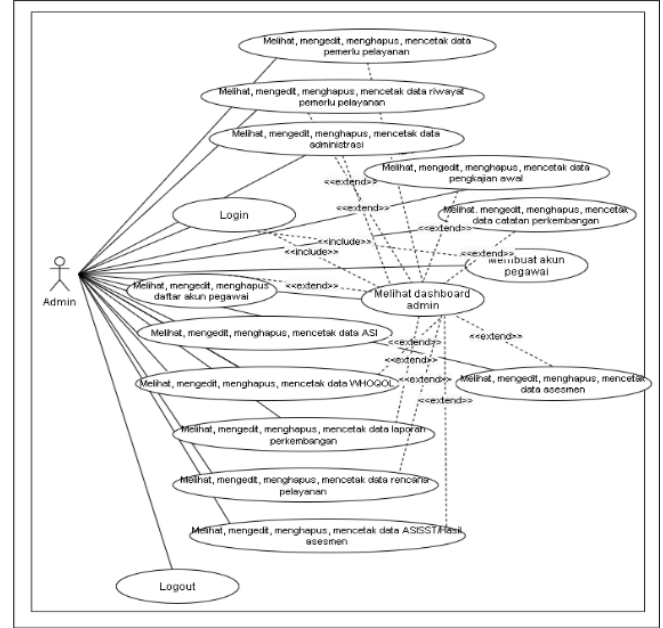

Gambar 3. Use Case Diagram

Pada Gambar 3 dijabarkan peran admin yaitu login, logout, dan dapat melihat, mengedit, menghapus, mencetak seluruh data-data rehabilitasi pada sistem informasi rehabilitasi korban penyalahgunaan NAPZA. Setelah use case diagram dibuat, kemudian disusun class diagram dalam perancangan database. Class diagram sistem informasi rehabilitasi korban penyalahgunaan NAPZA ditunjukkan pada Gambar 4.

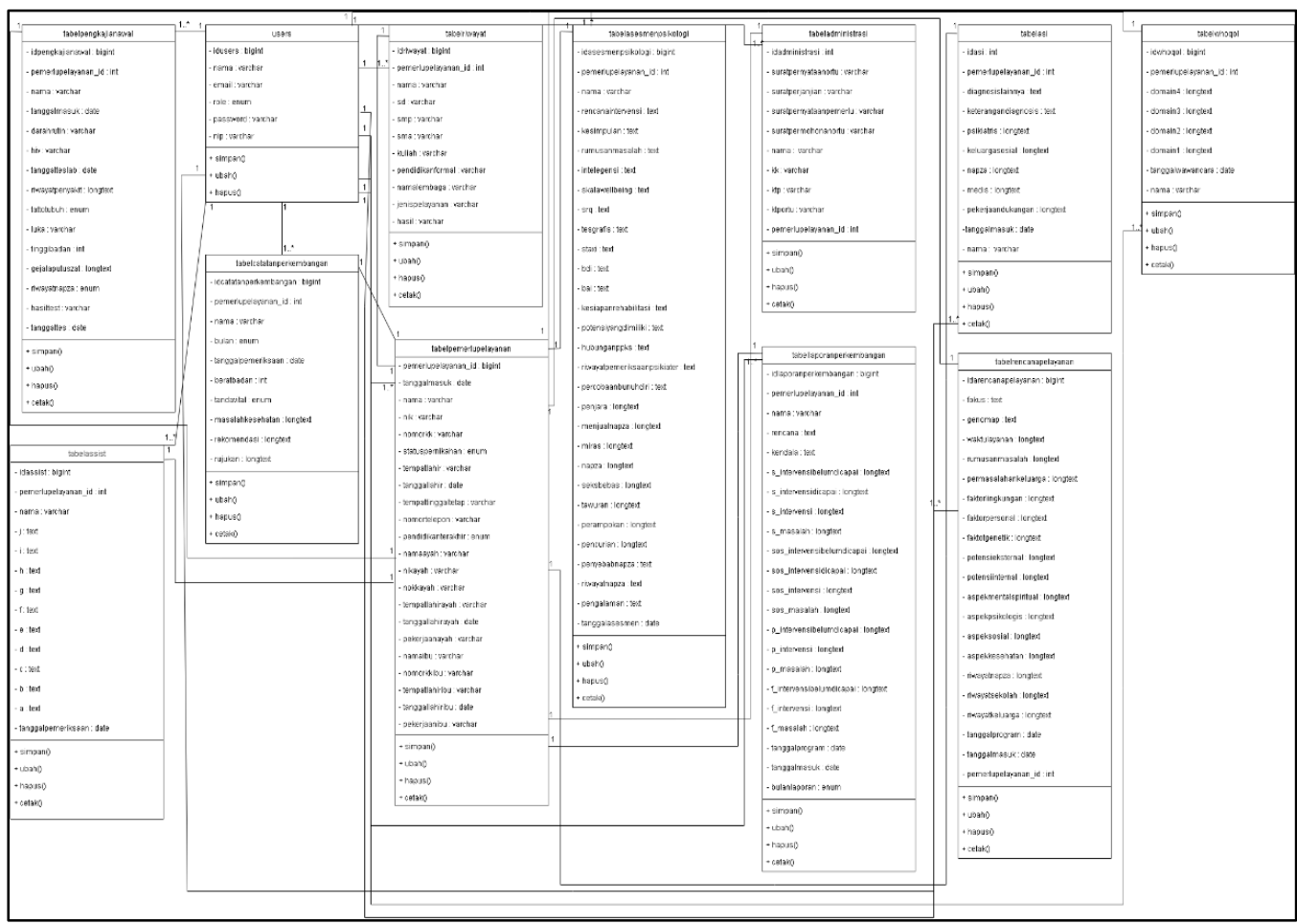

Gambar 4. Class Diagram

3. Implementation and Unit Testing

Pada tahap ini sistem informasi rehabilitasi telah dibangun dan diterapkan pada Kantor BRSKPN Satria. Selanjutnya sistem ini dilakukan pengujian unit testing dengan cara menguji satu per satu task pada sistem informasi menggunakan metode black box testing. 
4. Integration and System Testing

Pada tahap ini integrasi sistem dilakukan dengan cara menghosting sistem pada browser agar berjalan sesuai dengan fungsinya. Selanjutnya dilakukan system testing dengan uji coba sistem informasi yang dijalankan pada browser.

5. Operation and Maintenance

Pada tahap ini dilakukan pengoperasian sistem informasi kepada pegawai Kantor BRSKPN Satria dan memastikan bahwa sistem informasi tetap dapat diakses pada browser.

\section{Hasil dan Pembahasan}

Penerapan metode waterfall menghasilkan sebuah sistem informasi rehabilitasi korban penyalahgunaan NAPZA berbasis website.

1. Hasil Implementation System

Pada tahap implementasi sistem dilakukan pembuatan kode program mengacu pada rancangan yang telah dibuat. Hasil implementasi sistem informasi rehabilitasi korban penyalahgunaan NAPZA ditunjukkan pada Gambar 5. Pada halaman utama atau dashboard admin terdapat menu yang terdiri dari tabel asesmen, perawat, peksos, psikolog, dan akun pegawai.

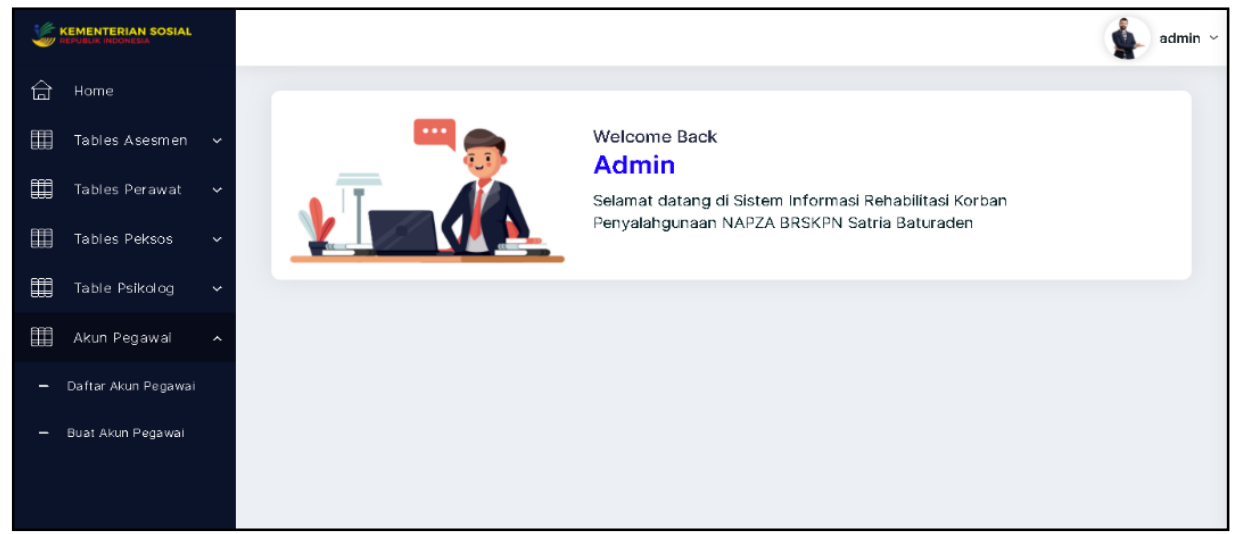

Gambar 5. Dashboard Admin

Tampilan halaman daftar akun pegawai ditunjukkan pada Gambar 6. Pada tampilan tersebut terdapat tabel pegawai yang telah diinputkan oleh admin.

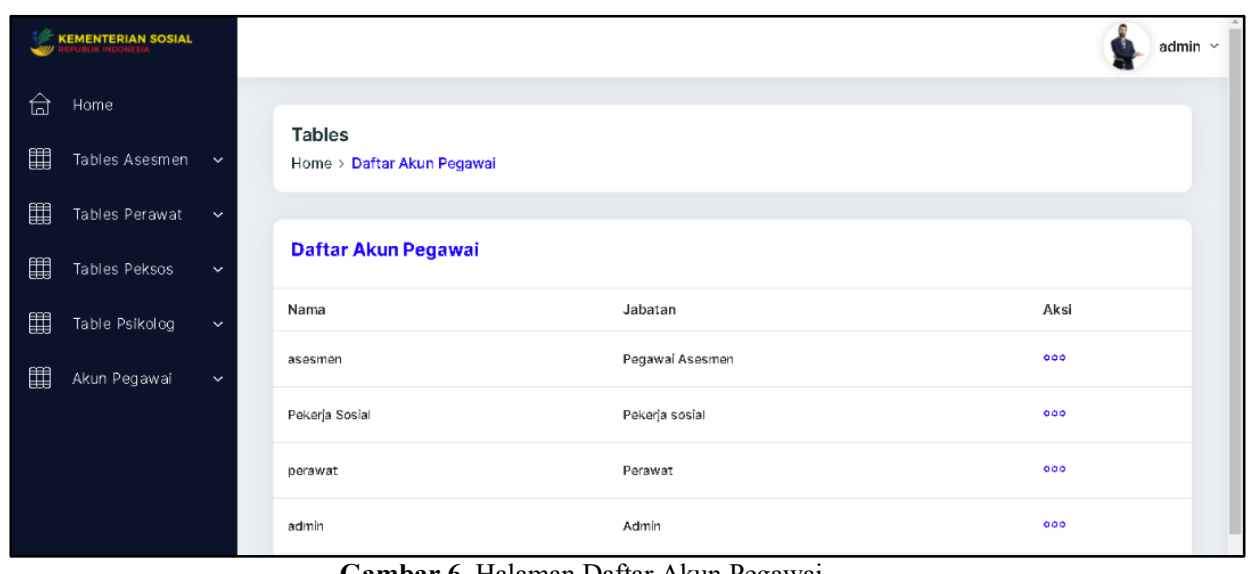

Gambar 6. Halaman Daftar Akun Pegawai

Tampilan cetak data WHOQOL ditunjukkan pada Gambar 7. Pada tampilan tersebut terdapat hasil WHOQOL yang telah diinputkan oleh pekerja sosial. 


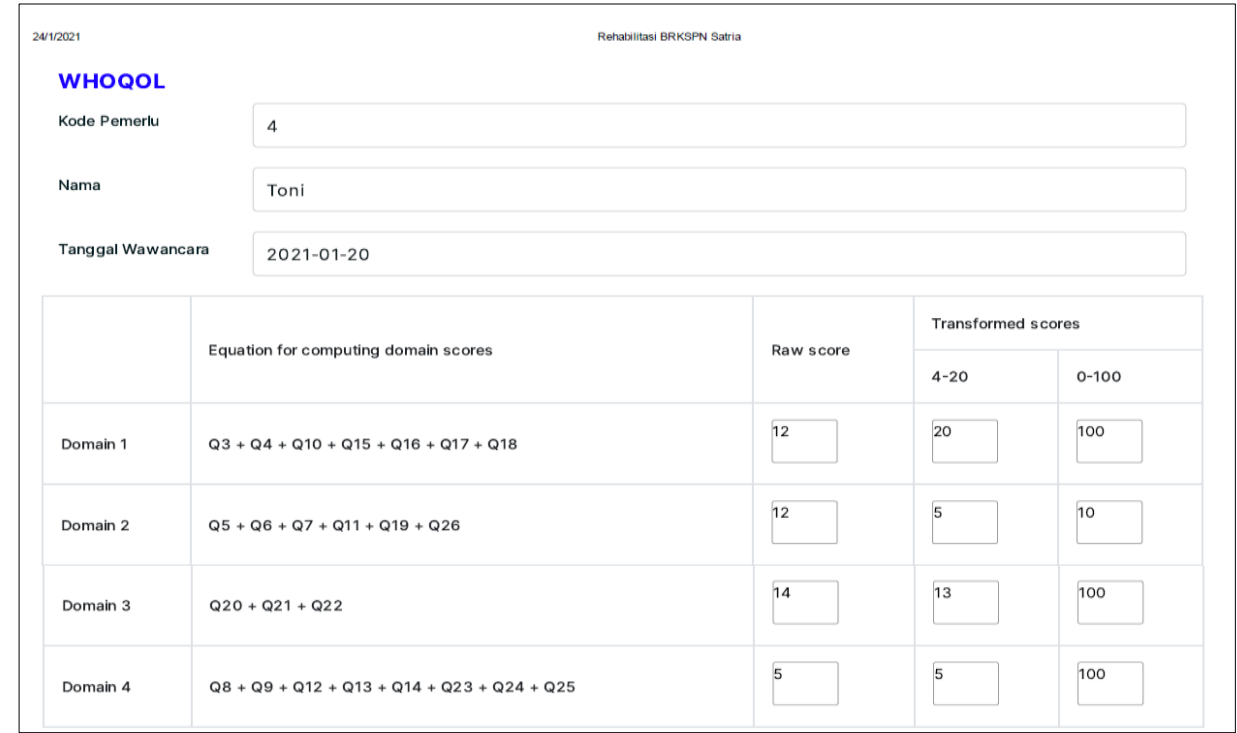

Gambar 7. Hasil Cetak Data $W H O Q O L$

Tampilan hasil cetak data asesmen ditunjukkan pada Gambar 8. Pada tampilan tersebut terdapat hasil asesmen yang telah diinputkan oleh pekerja sosial.

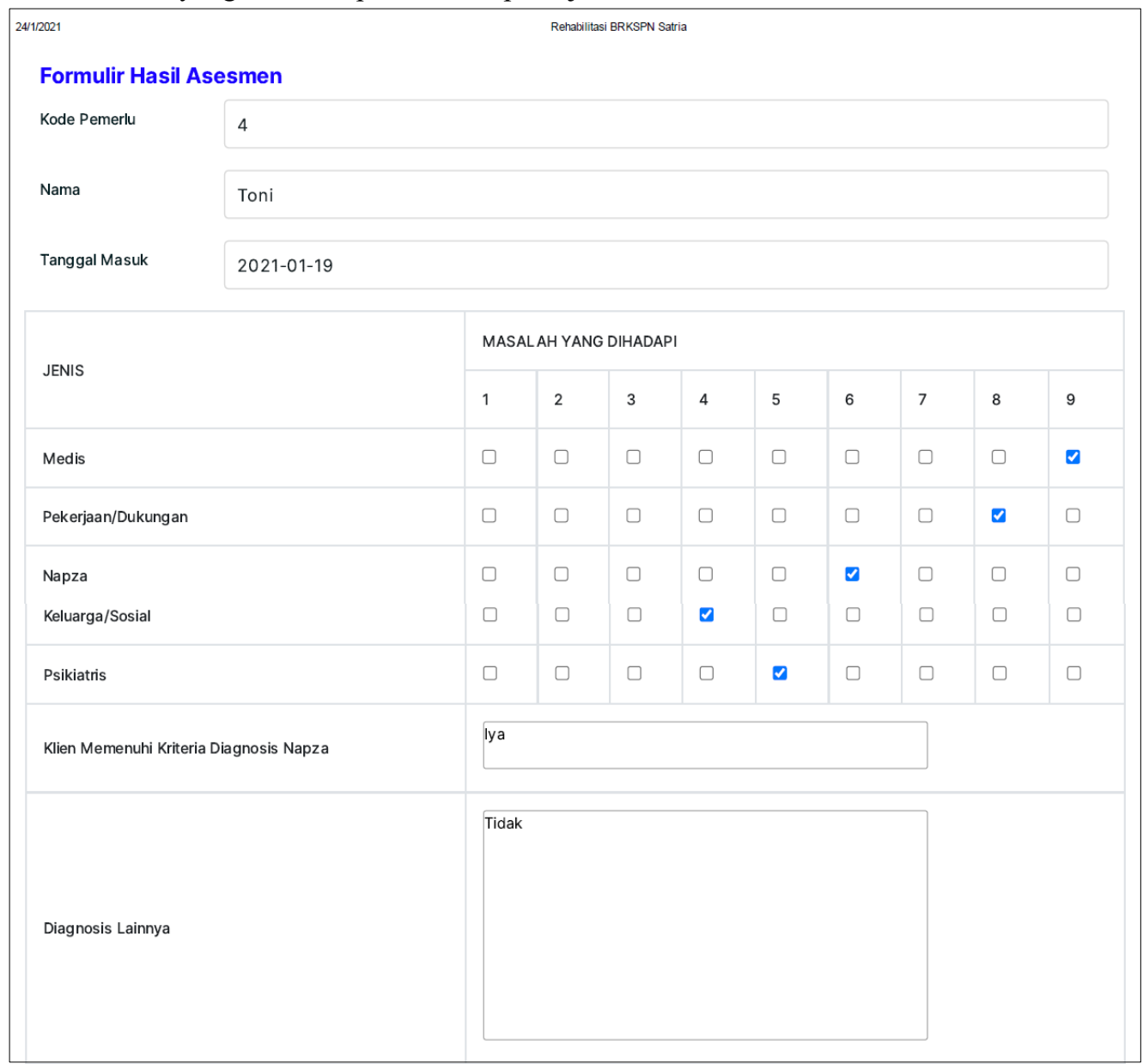

Gambar 8. Hasil Cetak Data Asesmen 
Tampilan halaman edit and view ditunjukkan pada Gambar 9. Pada halaman tersebut terdapat menu edit, view, dan cetak data rehabilitasi.

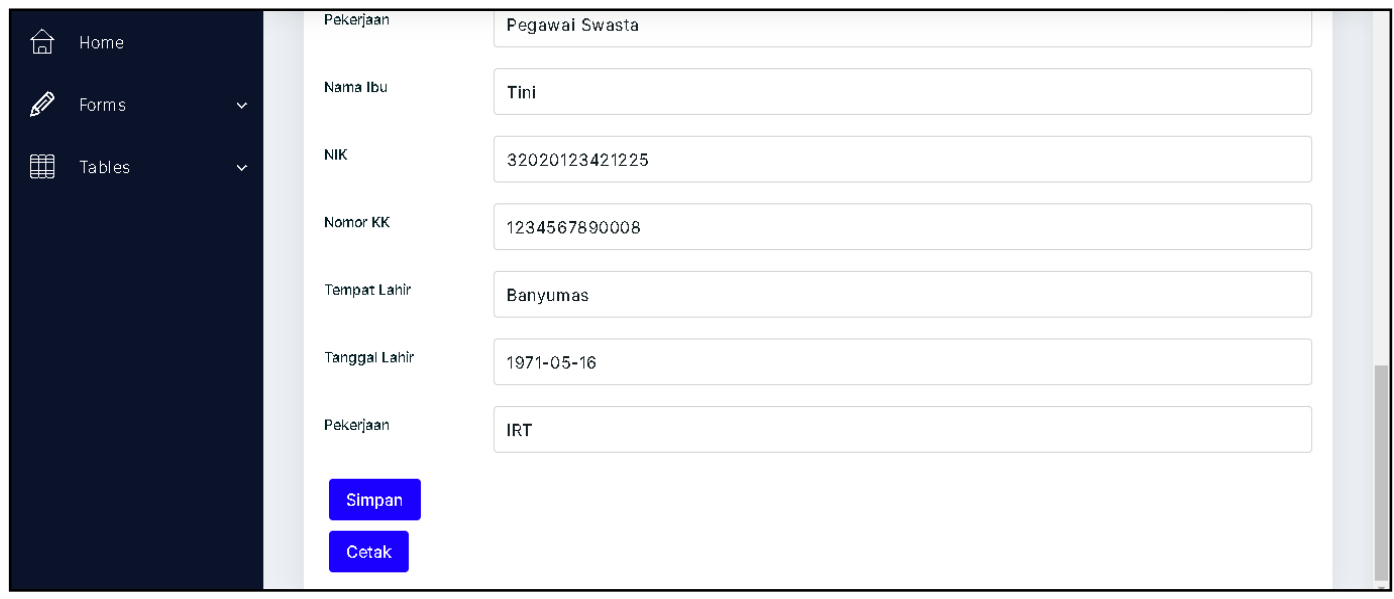

Gambar 9. Halaman Edit and View

\section{Hasil Unit Testing}

Pengujian atau unit testing dilakukan menggunakan black box testing, untuk memverifikasi dan memvalidasi fungsi pada sistem berjalan dengan benar. Pengujian unit testing dilakukan oleh developer system kepada pihak manajemen Kantor BRSKPN Satria. Hasil pengujian sistem informasi rehabilitasi ditunjukkan pada Tabel 1.

Tabel 1. Unit Testing

\begin{tabular}{c|l|l|l}
\hline No & \multicolumn{1}{|c|}{ Uji Coba } & \multicolumn{1}{c}{ Proses } & Hasil \\
\hline 1 & Form login admin & Input username dan password & Berhasil \\
2 & Menu utama admin & Tampil jika login sukses & Berhasil \\
3 & Data asesmen admin & View, edit, delete, dan cetak & Berhasil \\
4 & Data pekerja sosial & View, edit, delete, dan cetak & Berhasil \\
5 & Data perawat admin & View, edit, delete, dan cetak & Berhasil \\
6 & Data psikolog admin & View, edit, delete, dan cetak & Berhasil \\
7 & Form akun pegawai & Input data dan simpan & Berhasil \\
8 & Tabel akun pegawai & Edit, delete & Berhasil \\
9 & Logout admin & Klik logout & Berhasil \\
10 & Data perawat admin & View, edit, delete, dan cetak & Berhasil \\
\hline
\end{tabular}

3. Hasil Integration and System Testing

Sistem informasi rehabilitasi korban penyalahgunaan NAPZA yang telah diuji per bagian, selanjutnya disatukan menjadi sebuah sistem yang utuh dan diuji secara keseluruhan pada sebuah browser. Sistem informasi yang telah dirancang dilakukan sebuah hosting agar dapat diakses menggunakan internet. Sistem yang sudah dihosting kemudian dilakukan pengujian. Dalam pengujian ini dilakukan oleh developer system kepada 10 pengguna sistem rehabilitasi korban penyalahgunaan NAPZA di Kantor BRSKPN Satria Hasil system testing ditunjukkan pada Tabel 2.

Tabel 2. System Testing

\begin{tabular}{c|l|l|l|l}
\hline No & \multicolumn{1}{|c|}{ Browser } & \multicolumn{1}{|c|}{ Versi } & Hasil & Keterangan \\
\hline 1 & Google Chrome & 88.0 .4324 .104 & Berhasil & $\begin{array}{l}\text { Aplikasi dapat dijalankan sesuai } \\
\text { dengan fungsinya } \\
\text { Aplikasi dapat dijalankan sesuai } \\
\text { dengan fungsinya }\end{array}$ \\
\hline
\end{tabular}

4. Hasil Operation and Maintenance

Pada tahap operation, sistem informasi rehabilitasi diterapkan dan dioperasikan secara langsung oleh pegawai Kantor BRSKPN Satria. Sedangkan pada tahap maintenance dilakukan peningkatan 
layanan sistem informasi dengan cara memastikan bahwa server hositng harus tetap berjalan agar sistem tetap dapat diakses kapanpun pada browser menggunakan jaringan internet.

5. Pembahasan

Berdasarkan penelitian yang telah dilakukan, penelitian ini mempunyai lima tahapan sesuai dengan metode waterfall. Dari tahap awal sampai akhir metode waterfall menunjukkan bahwa tingkat keberhasilan penerapan sistem informasi berjalan sesuai dengan fungsionalitas dan kebutuhan pegawai Kantor BRSKPN Satria. Hal ini membuktikan bahwa sistem informasi dapat dan layak digunakan sebagai alat bantu pegawai untuk melakukan pelayanan rehabilitasi korban penyalahgunaan NAPZA.

\section{Kesimpulan}

Berdasarkan hasil penelitian dan pembahasan pada sistem informasi rehabilitasi dapat ditarik kesimpulan bahwa sistem informasi rehabilitasi korban penyalahgunaan NAPZA berhasil diterapkan dengan metode waterfall. Hal ini dapat diketahui berdasarkan kesesuaian setiap tahapannya yang dikerjakan secara urut. Sistem informasi rehabilitasi mampu menggantikan proses pendataan pasien rehabilitasi, perhitungan indikator keberhasilan rehabilitasi hingga pendokumentasian laporan korban penyalahgunaan NAPZA. Hasil dari tahap integration and system testing serta tahap operation and maintenance menyatakan bahwa sistem informasi rehabilitasi dapat diakses pada sebuah browser. Pengoperasian sistem informasi rehabilitasi pada pegawai Kantor BRSKPN dapat digunakan dengan baik dan meningkatkan kemampuan mengolah, mengelola, menyalurkan, serta mendistribusikan informasi guna mempermudah koordinasi dan proses pengambilan keputusan pada proses layanan rehabilitasi Kantor BRSKPN Satria.

\section{Daftar Pustaka}

[1] A. S. Putra, N. P. Rai Yuliartini, and D. G. S. Mangku, "Sistem Pembinaan terhadap Narapidana Narkotika di Lembaga Pemasyarakatan kelas II b Singaraja," e-Journal Komunitas Yustisi, vol. 2, no. 1, pp. 1-10, 2019.

[2] Badan Narkotika Nasional Republik Indonesia, Indonesia Drugs Report 2019. 2019.

[3] S. Akbar and F. Latifah, "Implementasi Framework Laravel Pada Sistem Informasi Sekolah Menggunakan Metode Waterfall Berbasis Web ( studi kasus sekolah luarbiasa Matahati Jakarta JISAMAR ( Journal of Information System , Applied , Management, Accounting and Researh ) e-ISSN : 2598,” vol. 3, no. 4, pp. 4553, 2019.

[4] N. BLACKLOCK and C. BLACKLOCK, "Penggunaan Metode Waterfall Untuk Pengembangan Sistem Monitoring Dan Evaluasi Pembangunan Pedes," Gooseberry, vol. XII, no. 01, pp. 41-56, 2018.

[5] V. O. Carvalho, "Left atrial volume and exercise capacity in adult heart transplant recipients," J. Cardiothorac. Surg., vol. 6, no. 1, pp. 233-238, 2011.

[6] A. F. Zuhri, A. Ahmad, I. Parlina, and R. Dewi, "Sistem Informasi Data Rehabilitasi Narkoba Pada Badan Narkotika Nasional Kota ( BNNK ) Pematangsiantar," pp. 255-260, 2020.

[7] N. Putri and E. Manik, "Sistem Informasi Berbasis Web Pada Badan Narkotika Nasional (Bnn) Kota Binjai," J. Inform. Kaputama(JIK), vol. 2, no. 1, 2018.

[8] G. W. N. Mardiah Nasution, Rusdiyanto Roestam, "Analisis Dan Perancangan Sistem Informasi Pengolahan Data Residen Menggunakan Basis Data Terdistribusi Pada Badan Narkotika Nasional Provinsi Sumatera Utara," Inf. Komput. Log., vol. Vol 1, No, 2018.

[9] A. Tipprom, P. Soontornpipit, J. Sillabutra, P. Satitvipawee, and C. Viwatwongkasem, "Development of a Rehabilitation Monitoring System on Web-Based Application for Patients with Knee Pain," iEECON 2018 6th Int. Electr. Eng. Congr., pp. 1-4, 2018.

[10] S. Liu and J. Wei, "The Satelite on the Research of the Software Life Cycle: V + Iterative Waterfall," Proc. 2018 2nd IEEE Adv. Inf. Manag. Commun. Electron. Autom. Control Conf. IMCEC 2018, no. Imcec, pp. 1716-1720, 2018.

[11] I. Wahyudi, S. Bahri, and P. Handayani, “Aplikasi Pembelajaran Pengenalan Budaya Indonesia,” vol. V, no. 1, pp. 135-138, 2019.

[12] G. Eko, Y. Yunita, and H. Amalia, "Rancang Bangun Sistem Informasi Pelayanan Jasa Home Service Dengan Model Waterfall Pada CV. Gian Motor Autoservice,” J. Perspekt., vol. 17, no. 1, pp. 17-21, 2019. 